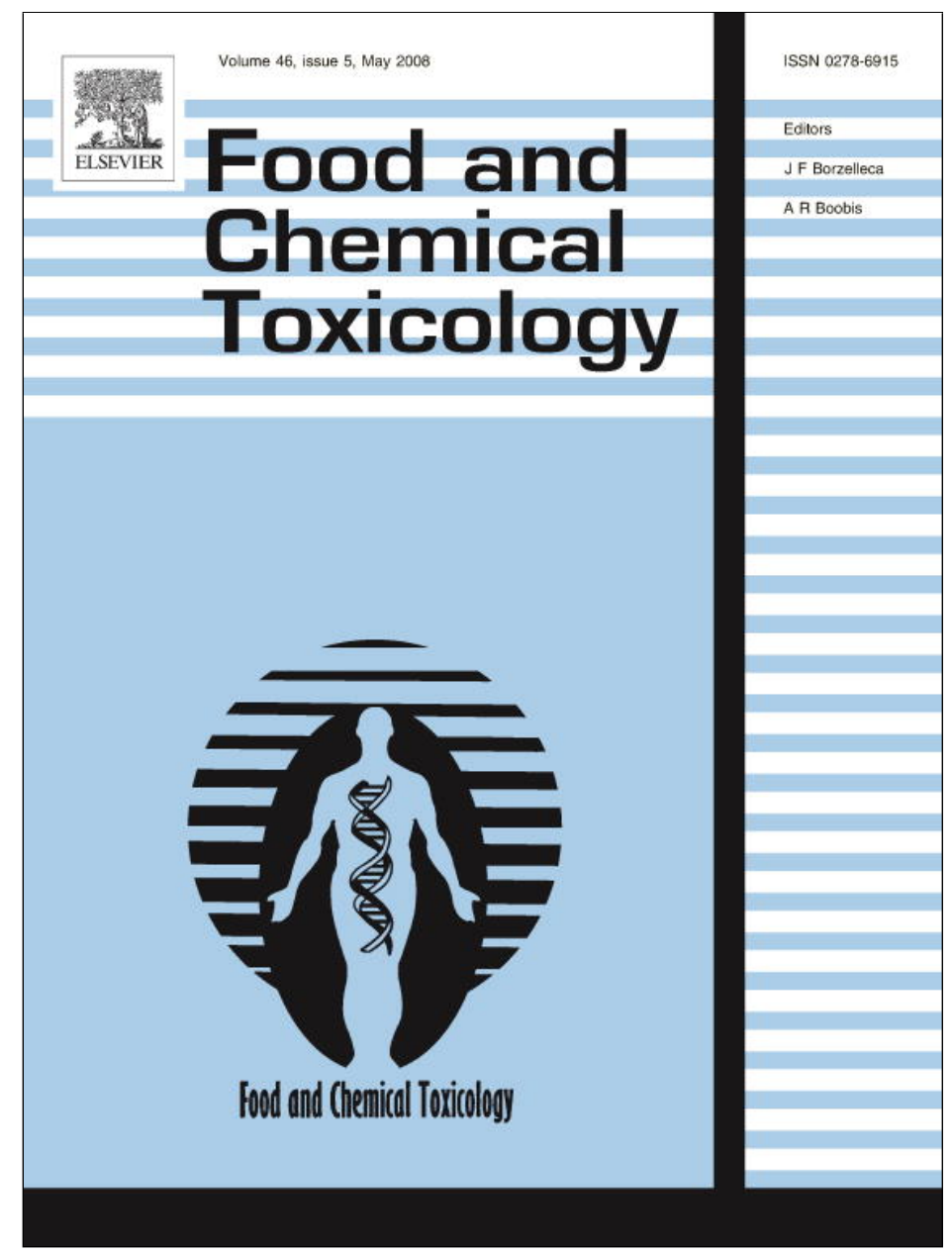

This article appeared in a journal published by Elsevier. The attached copy is furnished to the author for internal non-commercial research and education use, including for instruction at the authors institution and sharing with colleagues.

Other uses, including reproduction and distribution, or selling or licensing copies, or posting to personal, institutional or third party websites are prohibited.

In most cases authors are permitted to post their version of the article (e.g. in Word or Tex form) to their personal website or institutional repository. Authors requiring further information regarding Elsevier's archiving and manuscript policies are encouraged to visit: 


\title{
Chemical composition, and antioxidant and antimicrobial activities of three hazelnut (Corylus avellana L.) cultivars
}

\author{
Ivo Oliveira, Anabela Sousa, Jorge Sá Morais, Isabel C.F.R. Ferreira, Albino Bento, \\ Letícia Estevinho, José Alberto Pereira* \\ CIMO/Escola Superior Agrária, Instituto Politécnico de Bragança, Campus Sta Apolónia, Apartado 1 172, 5301-855 Bragança, Portugal
}

Received 4 December 2007; accepted 12 January 2008

\begin{abstract}
Hazelnut (Corylus avellana L.) is a very popular dry fruit in the world being consumed in different form and presentations. In the present work, three hazelnut cultivars ( $c v$. Daviana, Fertille de Coutard and M. Bollwiller) produced in Portugal, were characterized in respect to their chemical composition, antioxidant potential and antimicrobial activity. The samples were analysed for proximate constituents (moisture, fat, crude protein, ash), nutritional value and fatty acids profile by GC/FID. Antioxidant potential was accessed by the reducing power assay, the scavenging effect on DPPH (2,2-diphenyl-1-picrylhydrazyl) radicals and $\beta$-carotene linoleate model system. Their antimicrobial capacity was also checked against Gram positive (Bacillus cereus, B. subtilis, Staphylococcus aureus) and Gram negative bacteria (Pseudomonas aeruginosa, Escherichia coli, Klebsiella pneumoniae) and fungi (Candida albicans, Cryptococcus neoformans). Results showed that the main constituent of fruits was fat ranging from $56 \%$ to $61 \%$, being the nutritional value around $650 \mathrm{kcal}$ per $100 \mathrm{~g}$ of fruits. Oleic was the major fatty acid varying between $80.67 \%$ in $c v$. F. Coutard and $82.63 \%$ in $c v$. Daviana, followed by linoleic, palmitic, and stearic acids. Aqueous hazelnut extract presented antioxidant activity in a concentration-dependent way, in general with similar behaviour for all cultivars. Hazelnut extracts revealed a high antimicrobial activity against Gram positive bacteria (MIC $0.1 \mathrm{mg} /$ $\mathrm{mL}$ ) showing a good bioactivity of these fruits.
\end{abstract}

(c) 2008 Elsevier Ltd. All rights reserved.

Keywords: Hazelnut; Nutritional value; Fatty acids; Antioxidant potential; Antimicrobial activity

\section{Introduction}

In 2004, over 8.5 million tons of nuts were produced throughout the world, almost 700 thousand tons of which were of hazelnuts (Corylus avellana L.). Turkey is the world's largest hazelnut producer, contributing approximately $70 \%$ to the total global production, followed by Italy $(12 \%)$, the United States $(6 \%)$, and Spain $(2 \%)$ (FAOSTAT). Portuguese production is still comparatively low and mostly restricted to small scattered orchards near the located at Beira Alta and Trás-os-Montes region (north interior of Portugal) (Silva et al., 2005).

\footnotetext{
* Corresponding author. Tel.: +351 273 303277; fax: +351 273325405. E-mail address: jpereira@ipb.pt (J.A. Pereira).
}

Due to their organoleptic characteristics, hazelnuts are consumed all over the world, not only as a fruit but also in a diversity of manufactured food products, such as snacks, chocolates, cereals, bakery, dairy, salad, entree, sauce, ice creams, and other dessert formulations (Ozdemir and Akinci, 2004; Amaral et al., 2006a). Hazelnut has found its way into nontraditional foods due to the recognition of its nutritional and nutraceutical properties. Among nut species, hazelnut plays a major role in human nutrition and health because of its special composition of fat (around $60 \%$ ), most of which are highly rich in monounsaturated fatty acids (mainly oleic acid), protein, carbohydrate, dietary fiber, vitamins (vitamin E), minerals, phytosterols (mainly $\beta$-sitosterol), squalene and antioxidant phenols (Alasalvar et al., 2003, 2006a). The antioxidant activity of some of these molecules is based on their ability to donate 
a hydrogen atom to free radicals. Because these compounds are able to scavenge free radicals, they are believed to have potential in the prevention of cancer, atherosclerosis, and diabetes (Alasalvar et al., 2003). Nowadays there is considerable evidence that the antioxidants contained in fruits, vegetables and beverages play an important role in the maintenance of health and in prevention of disease. Phenolic compounds and phytochemicals present in plant products possess antioxidant and antiradical activities. These phytochemicals and phenolic compounds provide protection against harmful effects of oxidative stress, caused namely by free radicals, and are also known to reduce risks of certain type of cancer (Fukuda et al., 2003; Proestos et al., 2005; Pereira et al., 2006; Seabra et al., 2006). Plant product can also be used as antimicrobial agents, with phenolics and polyphenolic fraction of plant composition as major interest compounds. There is growing interest in using natural antimicrobial compounds because of consumer's pressure on the food industry to avoid chemical preservatives and of the increasing resistance to antibiotics. With this regard the antimicrobial capacity of phenolic compounds has also been reported (Rauha et al., 2000; Puupponen-Pimiä et al., 2001; Proestos et al., 2005; Sousa et al., 2006; Pereira et al., 2006, 2007). In fact, there are recent reports about the antioxidant and antiradical activities in extracts of Turkish hazelnut kernel, hazelnut green leafy cover (Alasalvar et al., 2006b), and other hazelnut byproducts such as hazelnut tree leaf (Oliveira et al., 2007; Shahidi et al., 2007).

Several authors have published data on the general chemical composition of hazelnut (Alasalvar et al., 2003; Ozdemir and Akinci, 2004; Koksak et al., 2006), and particularly on lipid composition of hazelnut varieties cultivated in Turkey, Italy, and Spain (Parcerisa et al., 1995; Alasalvar et al., 2006a). Also the triacylglycerol profile, and tocopherol and tocotrienol contents were obtained in Portuguese varieties (Amaral et al., 2006a). However, nutritional and chemical compositions of hazelnuts are mostly referred to cultivar, ecology and cultural applications (Parcerisa et al., 1995; Koksak et al., 2006).

Recent recognition of nuts as "heart-healthy" foods by the food and drug administration (FDA) has provided a major boost to the image of nuts, including hazelnut. A high MUFA diet tends to raise HDL cholesterol and lower LDL-cholesterol and TAG concentrations (Parcerisa et al., 1995; Alasalvar et al., 2006a). Thus, hazelnut as an excellent source of MUFA may prove beneficial, preventing cholesterol-based atherosclerosis (Durak et al., 1999). Nuts protect against ischemic cardiovascular diseases, possibly due to their high MUFA and PUFA content. Thus, hazelnuts are not only a source of energy but they also provide certain compounds (MUFAs, PUFAs, vitamin E and natural sterols) that enhance the nutritional value of the human diet.

In a previous study, our research group reported the antioxidant potential and antimicrobial activity of hazel leaves (Oliveira et al., 2007). Besides the few studies on the antioxidant activity of Turkish hazelnut varieties already mentioned, nothing has been reported about the antioxidant activity of hazelnuts produced in other regions and cultivars or about antimicrobial potential of hazelnut in general. Also, more detailed research on the nutritional composition and health-promoting components, such as fatty acids, will enhance our knowledge and appreciation for the use of hazelnut and its products in a variety of food and specialty products.

In the present work, three hazelnut cultivars ( $c v$. Daviana, Fertille de Coutard and M. Bollwiller), ones of the most representatives and widely distributed in Portugal, were characterized in respect to their chemical composition, antioxidant potential and antimicrobial activity. The samples were analysed for proximate constituents (moisture, fat, crude protein, ash), nutritional value and fatty acids profile by GC/FID. Antioxidant potential was accessed by the reducing power assay, the scavenging effect on DPPH (2,2-diphenyl-1-picrylhydrazyl) radicals and $\beta$ carotene linoleate model system. We also demonstrate for the first time, as far as we know, the antimicrobial activity of hazelnut extracts studying their antimicrobial capacity against Gram positive (Bacillus cereus, B. subtilis, Staphylococcus aureus) and Gram negative bacteria (Pseudomonas aeruginosa, Escherichia coli, Klebsiella pneumoniae) and fungi (Candida albicans, Cryptococcus neoformans).

\section{Materials and methods}

\subsection{Samples}

Hazelnut fruits were obtained from three Corylus avellana L. cultivars: Daviana, Fertille de Coutard and M. Bollwiller and were collected on September 2006 in Bragança, northeast of Portugal $\left(41^{\circ} 47^{\prime} 47.50918^{\prime \prime} \mathrm{N}\right.$, $6^{\circ} 46^{\prime} 5.71990^{\prime \prime} \mathrm{W}, 744.341 \mathrm{~m}$ ). The orchard has a planting density of $3.5 \times 7 \mathrm{~m}$. The trees are ten years old, being pruned when necessary. No phytosanitary treatments were applied. The fruits, $\approx 2 \mathrm{~kg}$ per cultivar, were handpicked from the soil, dried in a stove (Memmert Schwabach 854, 1994) at $30^{\circ} \mathrm{C}$, in the dark, for five days. The fruits were put in plastic bags and frozen to $-20^{\circ} \mathrm{C}$ until the analyses. For sample characterization five groups of 50 fruits of each cultivar were selected and fruit, kernel and shell weight, yield (\% of fruit weight) and blank fruits (\%) were determined (Table 1).

\subsection{Samples preparation}

Before each kind of analysis (chemical, antioxidant and antimicrobial) the hazelnuts were manually cracked and shelled, and then chopped in an appliance mill (model A327R1, Moulinex, Spain). For fatty acid analysis, crude oil was obtained from finely chopped nuts (ca. $15 \mathrm{~g}$ ) extracted with light petroleum ether (b.p. $40-60^{\circ} \mathrm{C}$ ) in a Soxhlet apparatus, the remaining solvent was removed by vacuum distillation.

\subsection{Chemical analysis}

Analyses of moisture, total fat, ash, and protein contents were carried out in duplicate according to AOAC Official Methods (AOAC, 1995). Moisture was determined at $100\left( \pm 2{ }^{\circ} \mathrm{C}\right)(5 \mathrm{~g}$ test sample $)$ in a stove until constant weight. Total fat was determined by extracting a known weight of sample $(5 \mathrm{~g})$ with petroleum ether, using a Soxhlet apparatus; the ash content was determined by incineration at $600 \pm 15^{\circ} \mathrm{C}$. The crude protein content $(N \times 4.38)$ of the samples was estimated by the macroKjeldahl 
Table 1

Characterization of analyzed samples

\begin{tabular}{lllll}
\hline Cultivar & Fruit weight $(\mathrm{g})$ & Kernel weight $(\mathrm{g})$ & Shell weight $(\mathrm{g})$ & Yield $(\%$ fruit weight) \\
\hline Daviana & $2.46 \pm 0.19$ & $1.22 \pm 0.09$ & $1.24 \pm 0.10$ & $49.45 \pm 0.51$ \\
F. Coutard & $3.39 \pm 0.07$ & $1.38 \pm 0.04$ & $2.01 \pm 0.04$ & $4.00 \pm 2.24$ \\
M. Bollwiller & $2.66 \pm 0.05$ & $1.27 \pm 0.05$ & $1.38 \pm 0.03$ & $9.00 \pm 10.84$ \\
\hline
\end{tabular}

method. Carbohydrate content was estimated by difference of the other components using the following formula: carbohydrate content $=100 \%-(\%$ moisture + protein $+\%$ fat $+\%$ ash $)$. Energy was expressed as kilocalories, using the factors mentioned in the Portuguese Legislation (Decreto-Lei, 2004): Energy $(\mathrm{kcal})=4 \times(\mathrm{g}$ protein $+\mathrm{g}$ carbohydrate $)+9 \times($ g lipid $)$.

\subsection{Fatty acid composition}

Fatty acids were determined by gas chromatography with flame ionization detection (GL-FID) capillary column based on the following trans-esterification procedure: fatty acids were methylated with $5 \mathrm{~mL}$ of methanol:sulphuric acid:toluene $2: 1: 1(\mathrm{v} / \mathrm{v})$, during at least $12 \mathrm{~h}$ in a bath at $50{ }^{\circ} \mathrm{C}$ and $160 \mathrm{rpm}$; then the $5 \mathrm{~mL}$ of deionised water were added, to obtain phase separation; the FAME were recovered with $5 \mathrm{~mL}$ of diethyl ether by shaking in a vortex, and the upper phase was passed through a micro-column of sodium sulphate anhydrous, in order to eliminate the water; the sample was recovered in a vial with Teflon, and before injection the sample was filtered with $0.2 \mu \mathrm{m}$ nylon filter from Milipore. The fatty acid profile was analyzed with a DAN1 model GC 1000 instrument equipped with a split/splitless injector, a flame ionization detector (FID) and a Macherey-Nagel column $\left(30 \mathrm{~m} \times 0.32 \mathrm{~mm} \mathrm{ID} \times 0.25 \mu \mathrm{m} d_{f}\right)$. The oven temperature program was as follows: the initial temperature of the column was $50{ }^{\circ} \mathrm{C}$, held for $2 \mathrm{~min}$, then a $10^{\circ} \mathrm{C} / \mathrm{min}$ ramp to $240{ }^{\circ} \mathrm{C}$ and held for $11 \mathrm{~min}$. The carrier gas (hydrogen) flow-rate was $4.0 \mathrm{~mL} / \mathrm{min}$ (0.61 bar), measured at $50{ }^{\circ} \mathrm{C}$. Split injection $(1: 40)$ was carried out at $250^{\circ} \mathrm{C}$. For each analysis $1 \mu \mathrm{L}$ of the sample was injected in GC. The results were recorded and processed using CSW 1.7 software (DataApex 1.7) and expressed in relative percentage of each fatty acid, calculated by internal normalization of the chromatographic peak area. Fatty acids were identified by comparing the relative retention times of FAMEs peaks from samples with standards.

\subsection{Extract preparation}

For each cultivar, three powdered sub samples ( $\sim 5 \mathrm{~g} ; 20 \mathrm{mesh})$ were extracted with $250 \mathrm{~mL}$ of boiling water for $45 \mathrm{~min}$ and filtered through Whatman $n^{\circ} 4$ paper. The aqueous extract was frozen, lyophilized and redissolved in water at concentrations of $100 \mathrm{mg} / \mathrm{mL}$ and $5-50 \mathrm{mg} / \mathrm{mL}$ for antimicrobial and antioxidant activities assays, respectively.

\subsection{Determination of total phenol content}

Phenolic compounds concentration in the obtained extracts was estimated by a colorimetric assay based on procedures described by Singleton and Rossi (1965) with some modifications. Briefly, $1 \mathrm{~mL}$ of sample was mixed with $1 \mathrm{~mL}$ of Folin and Ciocalteu's phenol reagent. After $3 \mathrm{~min}$, $1 \mathrm{~mL}$ of saturated sodium carbonate solution was added to the mixture and adjusted to $10 \mathrm{~mL}$ with distilled water. The reaction was kept in the dark for $90 \mathrm{~min}$, after which the absorbance was read at $725 \mathrm{~nm}$ (Analytik Jena 200-2004 spectrophotometer). Gallic acid was used for constructing the standard curve $(0.01-0.4 \mathrm{mM})$. The results are expressed as $\mathrm{mg}$ of gallic acid equivalents/g of extract (GAEs).

\subsection{Antioxidant activity}

\subsubsection{Reagents}

BHA (2-tert-butyl-4-methoxyphenol), TBHQ (tert-butylhydroquinone) and $\alpha$-tocopherol were purchased from Sigma (St. Louis, MO,
USA). 2,2-Diphenyl-1-picrylhydrazyl (DPPH) was obtained from Alfa Aesar. All other chemicals were obtained from Sigma Chemical Co. (St. Louis, USA). Methanol was obtained from Pronalab (Lisboa, Portugal). Water was treated in a Mili-Q water purification system (TGI Pure Water Systems, USA).

\subsubsection{Reducing power assay}

The reducing power was determined according to a described procedure (Oyaizu, 1986; Ferreira et al., 2007). Various concentrations of sample extracts $(2.5 \mathrm{~mL})$ were mixed with $2.5 \mathrm{~mL}$ of $200 \mathrm{mmol} / \mathrm{L}$ sodium phosphate buffer ( $\mathrm{pH} 6.6$ ) and $2.5 \mathrm{~mL}$ of $1 \%$ potassium ferricyanide. The mixture was incubated at $50{ }^{\circ} \mathrm{C}$ for $20 \mathrm{~min}$. After incubation $2.5 \mathrm{~mL}$ of $10 \%$ trichloroacetic acid $(\mathrm{w} / \mathrm{v})$ were added and then the mixture was centrifuged at $1000 \mathrm{rpm}$ in a refrigerated centrifuge (Centorion K24OR2003), for $8 \mathrm{~min}$. The upper layer $(5 \mathrm{~mL})$ was mixed with $5 \mathrm{~mL}$ of deionised water and $1 \mathrm{~mL}$ of $0.1 \%$ of ferric chloride, and the absorbance was measured spectrophotometrically at $700 \mathrm{~nm}$. The extract concentration providing 0.5 of absorbance $\left(\mathrm{EC}_{50}\right)$ was calculated from the graph of absorbance registered at $700 \mathrm{~nm}$ against the correspondent extract concentration. BHA and $\alpha$-tocopherol were used as reference compounds.

\subsubsection{Scavenging effect assay}

The capacity to scavenge the 2,2-diphenyl-1-picrylhydrazyl (DPPH) free radical was monitored according to a method reported before (Hatano et al., 1988). Various concentrations of sample extracts $(0.3 \mathrm{~mL})$ were mixed with $2.7 \mathrm{~mL}$ of methanolic solution containing DPPH radicals $\left(6 \times 10^{-5} \mathrm{~mol} / \mathrm{L}\right)$. The mixture was shaken vigorously and left to stand in the dark until stable absorption values were obtained. The reduction of the DPPH radical was measured by monitoring continuously the decrease of absorption at $517 \mathrm{~nm}$. DPPH scavenging effect was calculated as percentage of DPPH discolouration using the equation: \% scavenging effect $=\left[\left(A_{\mathrm{DPPH}}-A_{\mathrm{S}}\right) / A_{\mathrm{DPPH}}\right] \times 100$, where $A_{\mathrm{S}}$ is the absorbance of the solution when the sample extract has been added at a particular level and $A_{\mathrm{DPPH}}$ is the absorbance of the DPPH solution. The extract concentration providing $25 \%$ inhibition $\left(\mathrm{EC}_{25}\right)$ was calculated from the graph of scavenging effect percentage against extract concentration. BHA and $\alpha$ tocopherol were used as reference compounds.

\subsection{4. $\beta$-carotene linoleate model system}

The antioxidant activity of hazelnut kernel extracts was evaluated according to a described procedure (Mi-Yae et al., 2003). $\beta$-Carotene solution was prepared by dissolving $2 \mathrm{mg}$ of $\beta$-carotene in $10 \mathrm{~mL}$ of chloroform. Two millilitres of this solution was placed in a $100 \mathrm{~mL}$ roundbottom flask. After chloroform removal, at $40^{\circ} \mathrm{C}$ under vacuum, $40 \mathrm{mg}$ of linoleic acid, $400 \mathrm{mg}$ of Tween 80 emulsifier, and $100 \mathrm{~mL}$ of distilled water were added to the flask under vigorous shaking. Aliquots $(4.8 \mathrm{~mL})$ of this emulsion were transferred into different test tubes containing $0.2 \mathrm{~mL}$ of different concentrations of hazelnut extracts. The tubes were shaken and incubated at $50{ }^{\circ} \mathrm{C}$ in a water bath. As soon as the emulsion was added to each tube, the zero time absorbance at $470 \mathrm{~nm}$ was measured. Absorbance readings were then recorded until the control sample had changed colour. A blank assay, devoid of $\beta$-carotene, was prepared for background subtraction. Antioxidant activity was calculated using the following equation: Antioxidant activity $=(\beta$-carotene content after $2 \mathrm{~h}$ of assay/initial $\beta$ carotene content) $\times 100$. The assays were carried out in triplicate and the results were expressed as mean values \pm standard deviations. The extract concentration providing $50 \%$ antioxidant activity $\left(\mathrm{EC}_{50}\right)$ was calculated from the graph of antioxidant percentage against extract concentration. TBHQ was used as reference compound. 


\subsection{Antimicrobial activity}

\subsubsection{Reagents}

Ampicillin and cycloheximide were of the highest available quality, and purchased from Merck (Darmstadt, Germany). Water was treated in a Mili-Q water purification system (TGI Pure Water Systems, USA).

\subsubsection{Microorganisms and culture conditions}

Microorganisms CECT were obtained from the Spanish type culture collection (CECT) of Valencia University, while microorganisms ESA were clinically isolated strains identified in Microbiology Laboratory of Escola Superior Agrária de Bragança. Gram+ (B. cereus CECT 148, B. subtilis CECT 498 and $S$. aureus ESA 7 isolated from pus) and Gram(E. coli CECT 101, P. aeruginosa CECT 108 and K. pneumoniae ESA 8 isolated from urine) bacteria, and fungi (Candida albicans CECT 1394 and Cryptococcus neoformans ESA 3 isolated from vaginal fluid) were used to screen antimicrobial activity of the three hazelnut cultivars. Microorganisms were cultured aerobically at $37^{\circ} \mathrm{C}$ (Scientific 222 oven model, 2003) in nutrient agar medium for bacteria, and at $30^{\circ} \mathrm{C}$ (Scientific 222 oven model, 2003) in sabouraud dextrose agar medium for fungi.

\subsubsection{Test assays for antimicrobial activity}

The screening of antibacterial activities against Gram + and Grambacteria and fungi and the determination of the minimal inhibitory concentration (MIC) were achieved by an adaptation of the agar streak dilution method based on radial diffusion (Hawkey and Lewis, 1994; Ferreira et al., 2004; Sousa et al., 2006). Suspensions of the microorganism were prepared to contain approximately $10^{8} \mathrm{cfu} / \mathrm{mL}$, and the plates containing agar medium were inoculated $(100 \mu \mathrm{L}$; spread on the surface). Each sample $(50 \mu \mathrm{L})$ was placed in a hole ( $3 \mathrm{~mm}$ depth, $4 \mathrm{~mm}$ diameter) made in the centre of the agar. The MIC was considered to be the lowest concentration of the tested sample able to inhibit the growth of bacteria after $24 \mathrm{~h}$ and fungi after $48 \mathrm{~h}$. The diameters of the inhibition zones corresponding to the MICs were measured using a ruler, with an accuracy of $0.5 \mathrm{~mm}$. Each inhibition zone diameter was measured three times (three different plates) and the average was considered. A control using only inoculation was also carried out.

\section{Results and discussion}

\subsection{Chemical analysis and fatty acid composition}

The proximate composition results of the three studied cultivars are showed in Table 2. Fat was the major compound, ranging from $56.3 \%$ in $c v$. Daviana to $61.6 \%$ in $c v$. M. Bollwiller. Moisture presented the lower values, between $3.0 \%$ in $c v$. Daviana and $5.6 \%$ in $c v$ F. Coutard. The caloric values ranged from $649.1 \mathrm{kcal}$ in $c v$. Daviana to $677.2 \mathrm{kcal}$ in $c v$. M. Bollwiller. Those values confirm that hazelnuts are an excellent source of energy. When comparing these result with the ones previously obtained for the same cultivars by Amaral et al. (2006b), some differences can be noticed, probably due to the different location of the orchard from where the samples were collected, as well as to the year of harvest. In fact, there are evidences that harvesting year and orchard location can influence the chemical composition of hazelnuts (Parcerisa et al., 1995; Amaral et al., 2006c).

Fatty acid profile of $c v$. Daviana is shown in Fig. 1 and fatty acid composition is listed in Table 3. Oleic acid is the predominant one, ranging from $80.67 \%$ in $c v$. F. Coutard and $82.63 \%$ in $c v$. Daviana. Linoleic acid was the second

Table 2

Proximate chemical composition (grams per $100 \mathrm{~g}$ of fresh weight) of three hazelnut cultivars grown in Portugal (mean \pm SD)

\begin{tabular}{|c|c|c|c|c|c|c|}
\hline Cultivar & Moisture & Crude protein & Total fat & Carbohydrates & Ash & Energy (kcal) \\
\hline Daviana & $3.0 \pm 0.0$ & $15.7 \pm 0.0$ & $56.3 \pm 2.29$ & $19.9 \pm 1.91$ & $5.2 \pm 0.38$ & 649.1 \\
\hline F. Coutard & $5.6 \pm 1.0$ & $14.8 \pm 0.14$ & $60.6 \pm 0.02$ & $14.4 \pm 0.97$ & $4.6 \pm 0.08$ & 662.2 \\
\hline M. Bollwiller & $3.5 \pm 0.9$ & $15.1 \pm 0.24$ & $61.6 \pm 0.06$ & $15.6 \pm 1.00$ & $4.2 \pm 0.28$ & 677.2 \\
\hline
\end{tabular}

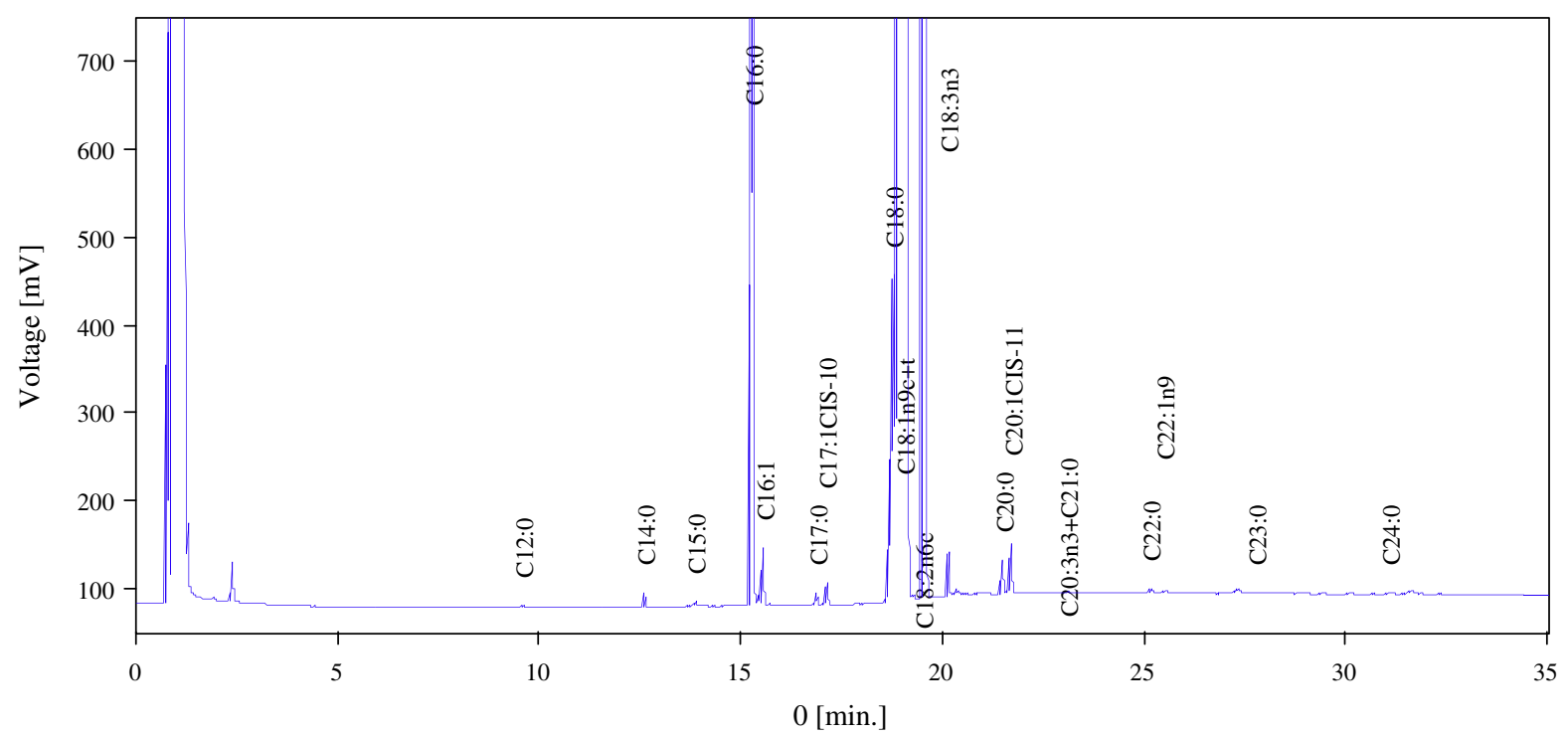

Fig. 1. GC-FID hazelnut $c v$. Daviana fatty acids profile. 
Table 3

Fatty acid composition (percent) of oil extracted from analyzed hazelnut samples (mean $\pm \mathrm{SD}$ )

\begin{tabular}{|c|c|c|c|}
\hline \multirow[t]{2}{*}{ Fatty acid } & \multicolumn{3}{|l|}{ Cultivar } \\
\hline & Daviana & F. Coutard & M. Bollwiller \\
\hline $\mathrm{C} 12: 0$ & $0.00 \pm 0.00$ & $0.00 \pm 0.00$ & $0.00 \pm 0.00$ \\
\hline $\mathrm{C} 14: 0$ & $0.03 \pm 0.00$ & $0.03 \pm 0.00$ & $0.04 \pm 0.00$ \\
\hline C15:0 & $0.01 \pm 0.00$ & $0.01 \pm 0.00$ & $0.01 \pm 0.00$ \\
\hline $\mathrm{C} 16: 0$ & $4.95 \pm 0.05$ & $5.35 \pm 0.03$ & $5.76 \pm 0.16$ \\
\hline C16:1 & $0.18 \pm 0.00$ & $0.21 \pm 0.00$ & $0.22 \pm 0.01$ \\
\hline $\mathrm{C} 17: 0$ & $0.04 \pm 0.00$ & $0.04 \pm 0.00$ & $0.05 \pm 0.00$ \\
\hline $\mathrm{C} 17: \ln 10 c$ & $0.08 \pm 0.00$ & $0.08 \pm 0.00$ & $0.07 \pm 0.00$ \\
\hline C18:0 & $1.78 \pm 0.14$ & $1.87 \pm 0.03$ & $1.74 \pm 0.38$ \\
\hline $\mathrm{C} 18: \ln 9 c+t$ & $82.63 \pm 0.25$ & $80.67 \pm 0.01$ & $81.16 \pm 0.13$ \\
\hline $\mathrm{C} 18: 2 \mathrm{n} 6 c$ & $9.84 \pm 0.05$ & $11.26 \pm 0.00$ & $10.43 \pm 0.08$ \\
\hline $\mathrm{C} 18: 3 \mathrm{n} 3$ & $0.15 \pm 0.00$ & $0.17 \pm 0.00$ & $0.19 \pm 0.00$ \\
\hline C20:0 & $0.11 \pm 0.00$ & $0.11 \pm 0.00$ & $0.14 \pm 0.00$ \\
\hline $\mathrm{C} 20: \ln 11 c$ & $0.16 \pm 0.00$ & $0.15 \pm 0.00$ & $0.13 \pm 0.00$ \\
\hline $\mathrm{C} 20: 3 \mathrm{n} 3+\mathrm{C} 21: 0$ & $0.00 \pm 0.00$ & $0.00 \pm 0.00$ & $0.00 \pm 0.00$ \\
\hline $\mathrm{C} 22: 0$ & $0.02 \pm 0.00$ & $0.02 \pm 0.00$ & $0.02 \pm 0.00$ \\
\hline $\mathrm{C} 22: \ln 9$ & $0.01 \pm 0.00$ & $0.01 \pm 0.00$ & $0.02 \pm 0.00$ \\
\hline $\mathrm{C} 23: 0$ & $0.01 \pm 0.00$ & $0.00 \pm 0.00$ & $0.01 \pm 0.00$ \\
\hline $\mathrm{C} 24: 0$ & $0.01 \pm 0.00$ & $0.01 \pm 0.00$ & $0.00 \pm 0.00$ \\
\hline Total SFA & 6.97 & 7.45 & 7.77 \\
\hline Total MUFA & 83.05 & 81.12 & 81.60 \\
\hline Total PUFA & 9.99 & 11.43 & 10.63 \\
\hline
\end{tabular}

most abundant fatty acid, followed by palmitic and stearic acids. All the other fatty acids were present in amounts lower than $1 \%$. Monounsaturated fatty acids (MUFA) were the major group of fatty acids, mainly due to the contribution of oleic acid. Polyunsaturated fatty acids (PUFA) and saturated fatty acids (SFA) were present in low percentages, PUFA ranging from $9.99 \%$ in $c v$. Daviana to $11.43 \%$ in $c v$. F. Coutard, and SFA from $6.97 \%$ in $c v$. Daviana to $7.77 \%$ in $c v$. M. Bollwiller. The quantification of total phenols content present in the different aqueous extracts (Table 4) revealed values from $11.17 \mathrm{mg} \mathrm{GAES} / \mathrm{g}$ in $c v$. F. Coutard to $14.77 \mathrm{mg}$ GAES/g in $c v$. Daviana.

\subsection{Antioxidant activity}

In the present study, the antioxidant potential of hazelnut kernel samples was measured by different chemical assays: reducing power, scavenging activity on DPPH radicals and lipid peroxidation inhibition by $\beta$-carotene-linoleate system. Results for the reducing power assay are shown in Fig. 2. From the analysis of the figure, we can observe that the extracts have a concentration-dependent

Table 4

Total phenolic contents ( $\mathrm{mg}$ GAES/g) and $\mathrm{EC}_{50}$ values $(\mathrm{mg} / \mathrm{mL})$ of hazelnut aqueous extracts

\begin{tabular}{lllll}
\hline Cultivar & $\begin{array}{l}\text { Total phenols } \\
\text { content }\end{array}$ & $\begin{array}{l}\text { Reducing } \\
\text { power }\left(\mathrm{EC}_{50}\right)\end{array}$ & $\begin{array}{l}\mathrm{DPPH} \\
\left(\mathrm{EC}_{25}\right)\end{array}$ & $\begin{array}{l}\beta \text {-Carotene } \\
\text { bleaching }\left(\mathrm{EC}_{25}\right)\end{array}$ \\
\hline Daviana & 14.77 & 1.87 & 2.91 & 1.72 \\
F. Coutard & 11.17 & 2.35 & $>5$ & 1.45 \\
M. Bollwiller & 11.45 & 2.65 & $>5$ & 1.76 \\
\hline
\end{tabular}

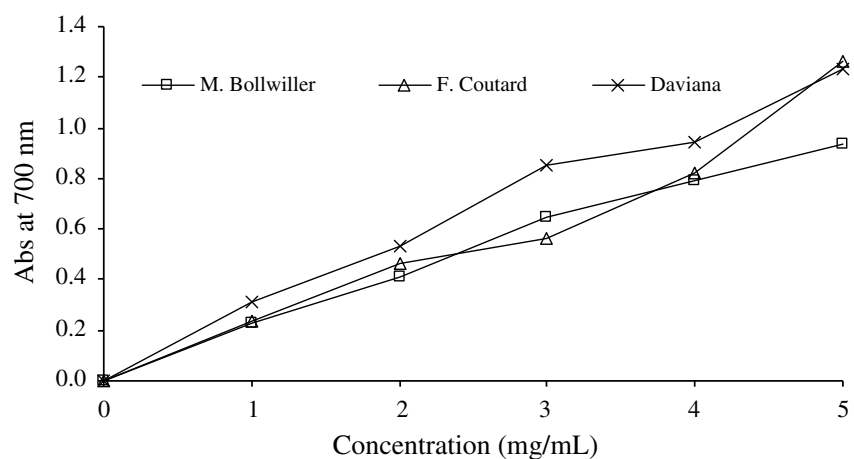

Fig. 2. Reducing power values of different hazelnut cultivars aqueous extracts. Each value is expressed as mean \pm standard deviation.

activity. The extracts showed to be more potent than BHA $\left(A_{700}=0.12\right.$ at $\left.3.6 \mathrm{mg} / \mathrm{mL}\right)$ and $\alpha$-tocopherol $\left(A_{700}=0.13\right.$ at $\left.8.6 \mathrm{mg} / \mathrm{mL}\right)$ standards. F. Coutard and Daviana were the cultivars with higher reducing power, presenting $c v$. Daviana the lower $\mathrm{EC}_{50}$ value (Table 4). The scavenging effect of hazelnut extracts on DPPH radicals also showed a concentration-dependent activity, especially for concentrations below $4 \mathrm{mg} / \mathrm{mL}$ (Fig. 3). Daviana

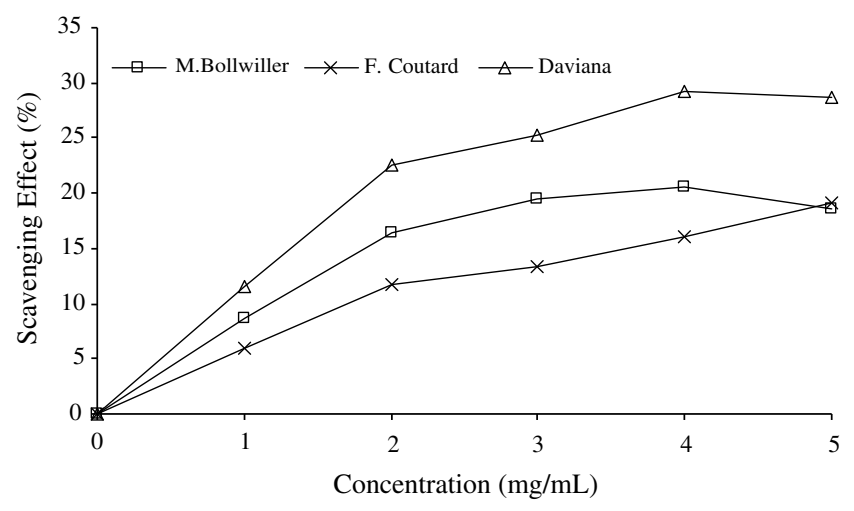

Fig. 3. Scavenging effect on DPPH of different hazelnut cultivars aqueous extracts. Each value is expressed as mean \pm standard deviation.

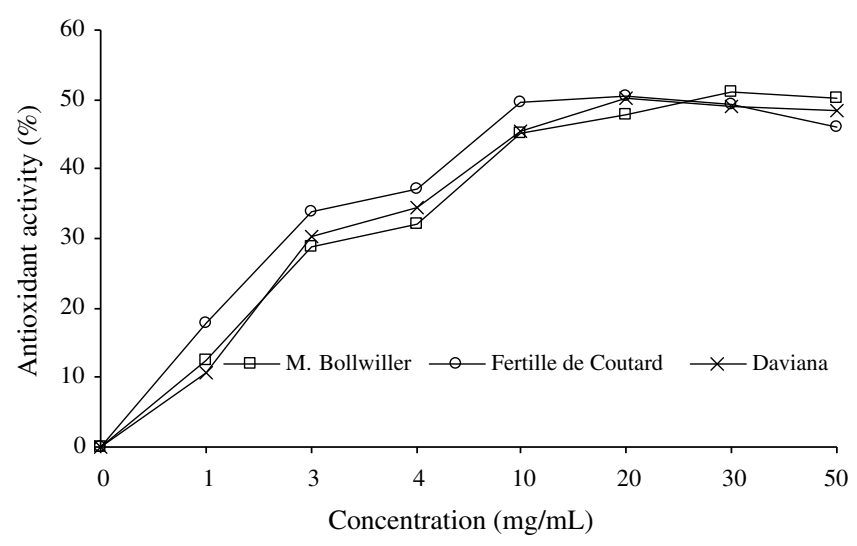

Fig. 4. Antioxidant activity ( $\%$ ) by $\beta$-carotene bleaching method of different hazelnut cultivars aqueous extracts. Each value is expressed as mean \pm standard deviation. 
Table 5

Antimicrobial activity of hazelnut aqueous extracts

\begin{tabular}{|c|c|c|c|c|c|c|c|c|}
\hline \multirow[t]{2}{*}{ Cultivar } & \multicolumn{8}{|l|}{$\mathrm{MIC}(\mathrm{mg} / \mathrm{mL})$} \\
\hline & B. cereus & B. subtilis & S. aureus & P. aeruginosa & E. coli & K. peumoniae & C. albicans & C. neoformans \\
\hline Daviana & $0.1(++++)$ & $0.1(+++)$ & $0.1(++++)$ & $100(-)$ & $100(-)$ & $100(-)$ & $100(-)$ & $100(-)$ \\
\hline F. Coutard & $0.1(+++)$ & $0.1(++++)$ & $0.1(++)$ & $100(-)$ & $100(-)$ & $100(-)$ & $100(-)$ & $100(-)$ \\
\hline M. Bollwiller & $0.1(++++)$ & $1(++++)$ & $0.1(++++)$ & $100(-)$ & $100(-)$ & $100(-)$ & $100(-)$ & $100(-)$ \\
\hline
\end{tabular}

No antimicrobial activity $(-)$, inhibition zone $<1 \mathrm{~mm}$. Slight antimicrobial activity $(+)$, inhibition zone $2-3 \mathrm{~mm}$. Moderate antimicrobial activity $(++)$, inhibition zone 4 $-5 \mathrm{~mm}$. High antimicrobial activity $(+++)$, inhibition zone $6-9 \mathrm{~mm}$. Strong antimicrobial activity $(++++)$, inhibition zone $>9 \mathrm{~mm}$. Standard deviation $\pm 0.5 \mathrm{~mm}$.

cultivar displayed the highest activity, while $c v$. F. Coutard displayed the lowest one. Only the results of $c v$. Daviana allowed an estimation of $\mathrm{EC}_{25}$ value (Table 4), while the other two cultivars did not even reach such scavenging effect activity. When comparing the results with standards BHA and $\alpha$-tocopherol, they proved to be very inferior to the ones of those reference compounds (BHA: $96 \%$ at $3.6 \mathrm{mg} / \mathrm{mL}$ and $\alpha$-tocopherol: $95 \%$ at $8.6 \mathrm{mg} / \mathrm{mL})$. The antioxidant activity of hazelnut extracts measured by the bleaching of $\beta$-carotene is shown in Fig. 4. The results obtained indicated a concentration-dependent antioxidant capacity, especially for concentrations below to $10 \mathrm{~g} / \mathrm{mL}$, and all the three cultivars showed resembling behaviour. $C v$. F. Coutard presented the lowest $\mathrm{EC}_{50}$ value and $c v$. M. Bollwiller the highest one (Table 4). These results fall short the one reached by TBHQ standard: $82.2 \%$ at $2 \mathrm{mg} / \mathrm{mL}$.

Table 4 allows an overview of the results, in which $c v$. Daviana showed higher values of total phenols and better results in the reducing power and scavenging activity on DPPH radicals assays, while $c v$. F. Coutard presented the best result in $\beta$-carotene bleaching inhibition.

Different works (Alasalvar et al., 2006b; Shahidi et al., 2007) reported better values for antioxidant activity of hazelnut's kernel extracts than the ones achieved in this work. This fact can be attributed to the extraction method of antioxidants. In the present work we adopt an extraction procedure previously validated and published for samples with a high quantity of fat (Sousa et al., 2008), using water as a polar solvent that exclude the non-polar components such as fat. Otherwise, water is an innocuous solvent and therefore more adequate solvent (no toxicity) for biological assays such as antioxidant and antimicrobial activities evaluation assays. However these aqueous extracts, have probably lower contents in antioxidants present in the fat fraction (mainly tocopherols) which could explain the different results obtained.

\subsection{Antimicrobial activity}

The minimal inhibitory concentration (MIC) values for bacteria (B. cereus, B. subtilis, S. aureus, E. coli, P. aerugin$o s a, K$. Pneumoniae) and fungi ( $C$. albicans and $C$. neoformans) were determined as an evaluation of the antimicrobial activity of the hazelnut samples and are presented in Table 5. The tested extracts only revealed high antimicrobial activity against Gram positive bacteria $(B$. cereus, B. subtilis, S. aureus), being Gram negative bacteria and fungi resistant to the tested extracts, at all the assayed concentrations. B. cereus was more susceptible than any of the Gram positive bacteria, presenting MICs of $0.1 \mathrm{mg} / \mathrm{mL}$ for $c v$. Daviana and M. Bollwiller, followed by $S$. aureus and B. subtilis. Daviana cultivar proved to be the most promissory cultivar, presenting the best results, with higher growth inhibition zones and lower MICs. Fruit extracts had a similar antimicrobial activity to hazel leaf extracts for the same cultivars (Oliveira et al., 2007) which were effective at low concentrations (around $0.1 \mathrm{mg} / \mathrm{mL}$ ); the present extracts are even better than table olive extracts previously studied by us (Pereira et al., 2006; Sousa et al., 2006). The antimicrobial agents added in food generally present problems related to some inherent toxicity (resistance, mutagenesis and carcinogenesis effects, for example) and natural compounds, such polyphenols have gained increasing importance. Phenolic compounds antimicrobial capacity is well known (Rauha et al., 2000; PuupponenPimiä et al., 2001; Proestos et al., 2005; Pereira et al., 2006, 2007) and we propose, for the first time, the use of hazelnut extracts as antimicrobials source. According to Borchers, Keen and Geratiwin, (Borchers et al., 2004), food extracts may be more beneficial than isolated constituents, because other compounds present in the extracts can change the properties of bioactive individual component.

In conclusion, as an excellent source of MUFA, hazelnuts may be beneficial, preventing cholesterol-based atherosclerosis and ischemic cardiovascular diseases. Besides their high energetic and nutritional value they also provide bioactive compounds such as antimicrobial and antioxidant agents, suggesting that these fruits could also be useful in the prevention of diseases in which free radicals are implicated.

\section{Conflict of interest statement}

The authors declare that there are no conflicts of interest.

\section{Acknowlwdgment}

The authors are grateful to INTERREG III A Program, Project PIREFI for financial support of this work. 


\section{References}

Alasalvar, C., Shahidi, F., Liyana-Pathirana, C., Ohshima, T., 2003. Turkish Tombul hazelnut (Corylus avellana L.). 1. Composition characteristics. J. Agric. Food Chem. 51, 3790-3796.

Alasalvar, C., Amaral, J.S., Shahidi, F., 2006a. Functional lipid characteristics of Turkish Tombul hazelnut (Corylus avellana L.). J. Agric. Food Chem. 54, 10177-10183.

Alasalvar, C., Karamac, M., Amarowicz, R., Shahidi, F., 2006b. Antioxidant and antiradical activities in extracts of hazelnut kernel (Corylus avellana L.) and hazelnut green leafy cover. J. Agric. Food Chem. 54, 4826-4832.

Amaral, J.S., Casal, S., Alves, M., Seabra, R., Oliveira, B., 2006 a. Tocopherol and tocotrienol content of hazelnut cultivars grown in Portugal. J. Agric. Food Chem. 54, 1329-1336.

Amaral, J.S., Casal, S., Citová, I., Santos, A., Seabra, R.M., Oliveira, B.P.P., 2006b. Characterization of several hazelnut (Corylus avellana L.) cultivars based in chemical, fatty acid and sterol composition. Eur. Food Res. Tech. 222, 274-280.

Amaral, J.S., Cunha, S., Santos, A., Alves, R., Seabra, R., Oliveira, B., 2006c. Influence of cultivar and environmental conditions on the triacylglycerol profile of hazelnut (Corylus avellana L.). J. Agric. Food Chem. 54, 449-456.

AOAC, 1995. Official Methods of Analysis, 16th ed., Association of Official Analytical Chemists, Arlington, VA, 1995.

Borchers, A.T., Keen, C.L., Gerstiwin, M.E., 2004. Mushrooms, tumors, and immunity: an update. Exp. Biol. Med. 229, 393-406.

Decreto-Lei $\mathrm{n}^{\circ}$ 167/2004 de 7 de Julho.

Durak, I., Koksal, I., Kaçmaz, M., Buyukkoçak, S., Çimen, B., Ozturk, H., 1999. Hazelnut supplementation enhances plasma antioxidant potential and lowers plasma cholesterol levels. Clin. Chim. Acta 284, 113-115.

Ferreira, I.C.F.R., Barros, L., Soares, M.E., Bastos, M.L., Pereira, J.A., 2007. Antioxidant activity and total phenolic contents of Olea europaea L. leaves sprayed with different copper formulations. Food Chem. 103, 188-195.

Ferreira, I.C.F.R., Calhelha, R.C., Estevinho, L.M., Queiroz, M.-J.R.P., 2004. Screening of antimicrobial activity of diarylamines in the 2,3,5trimethylbenzo $[b]$ thiophene series: a structure-activity evaluation study. Bioorg. Med. Chem. Lett. 14, 5831-5833.

FAO-STAT. Food and Agriculture Organization data. $<$ http://faostat.fao.org/faostat>.

Fukuda, T., Ito, H., Yoshida, T., 2003. Antioxidant polyphenols from walnuts (Juglans regia L.). Phytochemistry 63, 795-801.

Hatano, T., Kagawa, H., Yasuhara, T., Okuda, T., 1988. Two new flavonoids and other constituents in licorice root: their relative astringency and scavenging effects. Chem. Pharm. Bull. 36, 2090-2097.

Hawkey, P.M., Lewis, D.A., 1994. Medical Bacteriology - A Practical Approach. Oxford University, UK, pp. 181-194.

Koksak, A., Artik, N., Simsek, A., Gunes, N., 2006. Nutrient composition of hazelnut (Corylus avellana L.) varieties cultivated in Turkey. Food Chem. 99, 509-515.

Mi-Yae, S., Tae-Hun, K., Nak-Ju, S., 2003. Antioxidants and free radical scavenging activity of Phellinus baumii (Phellinus of Hymenochaetaceae) extracts. Food Chem. 82, 593-597.

Oliveira, I., Sousa, A., Valentão, P., Andrade, P., Ferreira, I.C.F.R., Ferreres, F., Bento, A., Seabra, R., Estevinho, L., Pereira, J.A., 2007.
Hazel (Corylus avellana L.) leaves as source of antimicrobial and antioxidative compounds. Food Chem. 105, 1018-1025.

Oyaizu, M., 1986. Studies on products of browning reactions: antioxidative activities of products of browning reaction prepared from glucosamine. Jpn. J. Nutr. 44, 307-315.

Ozdemir, F., Akinci, I., 2004. Physical and nutritional properties of four major commercial Turkish hazelnut varieties. J. Food Eng. 63, 341347.

Parcerisa, J., Rafecas, M., Castellote, A., Codony, R., Farran, A., Garcia, J., Gonzalez, C., Lopez, A., Romero, A., Boatella, J., 1995. Influence of variety and geographical origin on the lipid fraction of hazelnut (Corylus avellana L.) from Spain: (III) oli stability, tocopherol content and some mineral contents ( $\mathrm{Mn}, \mathrm{Fe}, \mathrm{Cu})$. Food Chem. 53, 71-74.

Pereira, J.A., Pereira, A.P.G., Ferreira, I.C.F.R., Valentão, P., Andrade, P.B., Seabra, R., Estevinho, L., Bento, A., 2006. Table olives from Portugal: phenolic compounds, antioxidant potential and antimicrobial activity. J. Agric. Food Chem. 54, 8425-8431.

Pereira, A.P., Ferreira, I.C.F.R., Marcelino, F., Valentão, P., Andrade, F., Seabra, R., Estevinho, L., Bento, A., Pereira, J.A., 2007. Phenolic compounds and antimicrobial activity of olive (Olea europaea L. Cv. Cobrançosa) leaves. Molecules 12, 1153-1162.

Puupponen-Pimiä, R., Nohynek, L., Meier, C., Kähkönen, M., Heinonen, M., Hopia, A., Oksman-Caldentey, K.-M., 2001. Antimicrobial properties of phenolic compounds from berries. J. Appl. Microbiol. 90, 494-507.

Proestos, C., Chorianopoulos, N., Nychas, G.-J.E., Komaitis, M., 2005. RP-HPLC analysis of the phenolic compounds of plant extracts. Investigation of their antioxidant capacity and antimicrobial activity. J. Agric. Food Chem. 53, 1190-1195.

Rauha, J.-P., Remes, S., Heinonen, M., Hopia, A., Kähkönen, M., Kujala, T., Pihlaja, K., Vuorela, H., Vuorela, P., 2000. Antimicrobial effects of Finnish plant extracts containing flavonoids and other phenolic compounds. Int. J. Food Microbiol. 56, 3-12.

Seabra, R.M., Andrade, P.B., Valentão, P., Fernandes, E., Carvalho, F., Bastos, M.L., 2006. Anti-oxidant compounds extracted from several plant materials. In: Fingerman, M., Nagabhushanam, R. (Eds.), Biomaterials from Aquatic and Terrestrial Organisms. Science Publishers, Enfield (New Hampshire), pp. 115-174.

Shahidi, F., Alasalvar, C., Liyana-Pathirana, C., 2007. Antioxidant phytochemicals in hazelnut kernel (Corylus avellana L.) and hazelnut by products. J. Agric. Food Chem. 55, 1212-1220.

Silva, A., Santos, F., Santos, A., Sousa, V., Lopes, A., Assunção, A., Carvalho, J., Borges, O., Ribeiro, R., Leme, P., Fernandes, S., Dias, R., Aguiar, F., 2005. A Aveleira. Tipografia Guerra. p. 179.

Singleton, V.L., Rossi Jr., J.A., 1965. Colorimetric of total phenolics with phosphomolybdic-phosphotungstic acid reagents. Am. J. Enol. Viticult. 16, 144-158.

Sousa, A., Ferreira, I.C.F.R., Barros, L., Bento, A., Pereira, J.A., 2008. Antioxidant potential of traditional stoned table olives "alcaparras": influence of the solvent and temperature extraction conditions. LWT Food Sci. Technol. 41, 739-745.

Sousa, A., Ferreira, I.C.F.R., Calhelha, R., Andrade, P.B., Valentão, P., Seabra, R., Estevinho, L., Bento, A., Pereira, J.A., 2006. Phenolics and antimicrobial activity of traditional stoned table olives "alcaparra". Bioorg. Med. Chem. 14, 8533-8538. 